\title{
Screening for Coronary Artery Disease in Kidney Transplant Candidates
}

\author{
Dana V. Rizk, MD, ${ }^{\text {a }}$ Samy Riad, MD, ${ }^{\text {b }}$ and Fadi G. Hage, MD, FASH, FACC,d \\ a Division of Nephrology, Department of Medicine, University of Alabama at Birmingham, \\ Birmingham, AL \\ b CHRISTUS Transplant Institute, South Texas Renal Care Group, San Antonio, TX \\ c Division of Cardiovascular Disease, Department of Medicine, University of Alabama at \\ Birmingham, Birmingham, AL \\ ' Section of Cardiology, Birmingham Veterans Affairs Medical Center, Birmingham, AL
}

Received Sep 21, 2014; accepted Sep 21, 2014

doi: $10.1007 / \mathrm{s} 12350-014-0006-2$

\section{See related article, pp. 282-296}

The latest United States Renal Data System Report indicated that there are more than 600,000 patients with end stage renal disease (ESRD) in the United States. ${ }^{1}$ Of these, about 90,000 patients are on the waiting list for kidney transplantation. While $38 \%$ were listed with inactive status, the remaining 55,371 patients are active candidates, a number three times that of the donor kidney pool. Not surprisingly, the median wait time on the renal transplant wait list continues to rise and has reached about 4.3 years for those newly listed in 2007 . $^{1}$ The gap between the large candidate pool and the shortage of donor organs poses special challenges with regard to allocation of organs and cardiac risk stratification of patients while on the waiting list.

A vast majority of potential renal transplant recipients have ESRD and are on some form of dialysis. ${ }^{2}$ Epidemiologic data show that cardiovascular mortality is the leading cause of death among patients with ESRD and by 20-40-fold higher than that of the general population. ${ }^{1,3,4}$ Similarly, cardiovascular risk is high even for patients with advanced chronic kidney disease (CKD), who are listed for transplantation before starting

Reprint requests: Fadi G. Hage MD, FASH, FACC, Division of Cardiovascular Disease, Department of Medicine, University of Alabama at Birmingham, Lyons Harrison Research Building 314, 1900 University BLVD, Birmingham, AL, 35294, USA; fadihage@uab.edu

J Nucl Cardiol 2015;22:297-300.

$1071-3581 / \$ 34.00$

Copyright (C) 2014 American Society of Nuclear Cardiology. dialysis. ${ }^{5}$ This cardiovascular risk is carried over posttransplant, and the number one reason for renal allograft loss is death with a functioning allograft due to cardiovascular cause claiming $36 \%$ of functioning allografts by 10 years after transplantation. Noteworthy, nearly half of the fatalities occurring in the first 30 days post operatively are due to acute myocardial infarctions. ${ }^{6}$

The evaluation of this high risk population in preparation for transplantation is different from that advocated by the American College of Cardiology (ACC)/American Heart Association (AHA) Guideline on Perioperative Cardiovascular Evaluation and Management of Patients Undergoing Non-cardiac Surgery. ${ }^{7}$ In this issue of the Journal, Parikh et $\mathrm{al}^{8}$ review the Scientific Statement From the AHA and the ACC for the Cardiac Disease Evaluation and Management Among Kidney and Liver Transplantation Candidates ${ }^{9}$ and highlight the challenges faced during the evaluation of these patients. We will focus our editorial on the kidney transplantation part of the Statement.

The Statement advocates for the delay or cancelation of transplantation in patients with active cardiac conditions such as unstable angina, recent myocardial infarction, severe stable angina, decompensated heart failure, significant arrhythmias, and severe valvular disease. ${ }^{9}$ The Statement then acknowledges that "there are no definitive data at this time for or against screening for myocardial ischemia among kidney transplantation candidates who are free of active cardiac conditions.' Parikh et al, ${ }^{8}$ state the case clearly and effectively against invasive or noninvasive coronary angiography as screening tool for coronary artery disease (CAD) in all transplant candidates. They summarize the diagnostic accuracy of noninvasive stress testing using myocardial perfusion imaging and stress echocardiography (Table $1 \mathrm{in}^{8}$ ) and 
indicate that it is comparable for both imaging modalities. They also describe the prognostic data available for both tests (Table $2 \mathrm{in}^{8}$ ) and conclude that "the choice of testing modality should be based upon the expertise of the particular transplant center." Therefore, the use of these noninvasive stress tests to select patients for coronary angiography seems to be a reasonable approach when applied to the appropriate populations.

A key step in this process is defining the population that requires further evaluation with stress imaging. While prior guidelines from the American Society of Transplantation advocated for stress testing in all patients with known CAD or diabetes, or who have two or more CAD risk factors (men aged 45 years or older, women aged 55 years or older, CAD in first degree relative, current tobacco smoking, hypertension, total cholesterol $>200 \mathrm{mg} \mathrm{dL}^{-1}, \mathrm{HDL}<25 \mathrm{mg} \mathrm{dL}^{-1}$, and left ventricular hypertrophy), ${ }^{10}$ the current approach limits testing to patients with multiple CAD risk factors, ${ }^{9}$ and defines these based on the factors adopted in the 2006 Lisbon Conference. ${ }^{11}$ These risk factors (diabetes, prior cardiovascular disease, $>1$ year on dialysis, left ventricular hypertrophy, age >60 years, smoking, hypertension, and dyslipidemia) are based on extensive epidemiologic studies and are not controversial, but other nontraditional risk factors have been described in the renal population, ${ }^{12,13}$ and there is certainly room for improvement in expanding the list and tailoring it to this specific population. Further, the specific number of these risk factors that should trigger testing is not well defined, as clearly stated by the Writing Committee which suggested three or more risk factors as a reasonable starting point. $^{9}$

An important consideration not addressed in the AHA/ACC Statement ${ }^{9}$ or in the review-by Parikh et $\mathrm{al}^{8}$ is the risk of contrast nephropathy associated with coronary angiography in this population. ${ }^{14}$ While angiographic contrast-induced acute kidney injury is usually not a major concern in ESRD patients on hemodialysis, it may impair the residual renal function required for peritoneal dialysis. More importantly, the risk-benefit ratio associated with coronary angiography in asymptomatic patients is less clear in those who have advanced kidney disease but are not yet on dialysis especially if they are being listed for transplantation from deceased donor when the waiting list may extend for several years.

With regard to the issue of cardiac surveillance while awaiting kidney transplantation, i.e., when to repeat noninvasive stress testing if initially negative, the AHA/ACC Statement admitted uncertainty regarding the usefulness of periodic screening. ${ }^{9}$ We note here that the 2005 National Kidney Foundation/Kidney Disease Outcomes Quality Initiative Guidelines recommended routine stress testing with imaging every year for patients with diabetes and ESRD regardless of the presence of symptoms, on the basis of fast progression of CAD in this population. ${ }^{15}$ The focus on patients with diabetes stems from the concern that prospective transplant candidates with diabetes seem to be a particularly high risk group. Twenty five to $40 \%$ of asymptomatic diabetics who underwent coronary angiography were found to have a significant CAD lesion in one or more vessels ${ }^{16}-{ }^{18}$ and the survival of patients with diabetes, ESRD, and significant CAD without coronary revascularization is poor. ${ }^{18}{ }^{20}$ The issue of repeat testing is particularly relevant since patients spend many years on the transplant waiting list, especially in areas of the country with a large CKD burden. ${ }^{1}$ We have certainly seen many examples of new and significant findings on routine repeat testing of patients while on the waiting list who had initial normal stress tests. Hakeem et al have shown that the annual cardiac death rate rises with progressively worsening renal function in patients with normal perfusion on stress imaging reaching almost 5\% in those with estimated glomerular filtration rate less than $30 \mathrm{~mL} \mathrm{~min}^{-1}$ / $1.73 \mathrm{~m}^{2} .^{21}$ However, routine annual or biennial stress testing in this large asymptomatic population raises serious questions regarding the appropriateness of such an approach in the absence of solid data demonstrating its usefulness. Currently, practice varies widely based on referral volumes and wait-listing time for each transplant center. For large volume centers with longer wait time, $\mathrm{CAD}$ evaluation may not take place early in the evaluation process but rather closer to the time of transplantation (i.e., when the candidate is higher up on the list). Although this strategy has the potential to minimize repeat imaging at routine intervals, it will increase the uncertainty of whether the candidates will be eligible for transplantation (expanding the waiting list), and may miss the opportunity to identify disease early in a population known to be at increased risk irrespective of whether or not transplantation is being considered.

Finally, more studies are needed to guide the management of patients based on the results of the noninvasive stress tests. There is currently a paucity of data to support prophylactic coronary revascularization in asymptomatic ESRD patients awaiting transplantation. A single randomized study has been performeds in this field which randomized 26 transplantation candidates with insulindependent diabetes and significant CAD on angiography to coronary revascularization vs. medical therapy (aspirin plus calcium channel blocker). ${ }^{22}$ Although this study demonstrated the potential benefit of revascularization after screening in this population, its small size and the outdated medical regimen that was used prohibit generalizing its findings to guide management today. Several observational studies have been reported. We have previously described the outcome of 3,698 patients with ESRD 
Table 1. Screening for coronary artery disease in kidney transplant candidates-unanswered questions

Should we screen for CAD in kidney transplant candidates?

How should we select the population for screening (what risk factors and how many)?

What imaging modality, if any, should we use?

When should we screen during the evaluation process and how often should we repeat testing?

How should the results of testing be used to guide management?

Should asymptomatic patients with high-risk stress tests undergo revascularization?

Should imaging be repeated if decision is to treat medically?

What is the best method for coronary revascularization in this population (percutaneous coronary intervention or coronary artery bypass grafting)?

Should patients with high-risk stress tests who underwent revascularization be eligible for transplantation? If yes, after how long?

evaluated for kidney transplantation at our institution and reported that the presence and severity of CAD on angiography were not predictive of survival and that coronary revascularization was associated with improved survival only in patients with 3 -vessel $\mathrm{CAD}^{23}$ The ongoing ISCHEMIA-CKD trial will randomize $\sim 1,000$ patients with advanced CKD with moderate to severe ischemia on stress testing to a routine invasive strategy with cardiac catheterization followed by revascularization plus optimal medical therapy vs. a conservative strategy of optimal medical therapy with catheterization and revascularization reserved for those who fail medical therapy. This important trial, the largest treatment strategy trial in severe CKD patients with stable CAD, which will enroll ESRD patients being evaluated for transplantation, will help fill the knowledge gap in this arena.

It is notable that the recommendations issued by the AHA/ACC Scientific Statement with regards to noninvasive stress testing are largely based on weak evidence and expert opinion (Class IIb, Level of Evidence C). ${ }^{9}$ In the absence of solid scientific data and evidence-based guidelines, clinicians in different transplant centers are likely to rely on their local expertise and experience to implement the suggested screening strategies. In order to make the best use of scarce resources such as solid organs, the risk stratification process should aim not only at the immediate risk related to the procedure but rather the long-term survival of the organ transplant recipients. More research is needed in this area to address many unanswered questions, some of which we list in Table 1.

\section{References}

1. U.S. Renal Data System, USRDS 2013 Annual Data Report: Atlas of Chronic Kidney Disease and End-Stage Renal Disease in the United States, National Institutes of Health, National Institute of Diabetes and Digestive and Kidney Diseases, Bethesda, MD, 2013.
2. Israni AK, Salkowski N, Gustafson S, Snyder JJ, Friedewald JJ, Formica RN, et al New national allocation policy for deceased donor kidneys in the United States and possible effect on patient outcomes. J Am Soc Nephrol 2014;25:1842-8.

3. Collins AJ, Li S, Ma JZ, Herzog C. Cardiovascular disease in endstage renal disease patients. Am J Kidney Dis 2001;38:S26-9.

4. Hage FG, Venkataraman R, Zoghbi GJ, Perry GJ, DeMattos AM, Iskandrian AE. The scope of coronary heart disease in patients with chronic kidney disease. J Am Coll Cardiol 2009;53:2129-40.

5. Go AS, Chertow GM, Fan D, McCulloch CE, Hsu CY. Chronic kidney disease and the risks of death, cardiovascular events, and hospitalization. New Engl J Med 2004;351:1296-305.

6. Ojo AO, Hanson JA, Wolfe RA, Leichtman AB, Agodoa LY, Port FK. Long-term survival in renal transplant recipients with graft function. Kidney Int 2000;57:307-13.

7. Fleisher LA, Fleischmann KE, Auerbach AD, Barnason SA, Beckman JA, Bozkurt B et al 2014 ACC/AHA Guideline on Perioperative Cardiovascular Evaluation and Management of Patients Undergoing Noncardiac Surgery: A Report of the American College of Cardiology/American Heart Association Task Force on Practice Guidelines. J Am Coll Cardiol 2014. doi: 10.1016/j.jacc.2014.07.945.

8. Parikh K, Appis A, Doukky R. Cardiac imaging for the assessment of patients being evaluated for kidney or liver transplantation. $\mathrm{J}$ Nucl Cardiol 2014. doi:10.1007/s12350-014-9997-y.

9. Lentine KL, Costa SP, Weir MR, Robb JF, Fleisher LA, Kasiske $\mathrm{BL}$, et al Cardiac disease evaluation and management among kidney and liver transplantation candidates: A scientific statement from the American Heart Association and the American College of Cardiology Foundation. J Am Coll Cardiol 2012;60:434-80.

10. Kasiske BL, Cangro CB, Hariharan S, Hricik DE, Kerman RH, Roth D, et al The evaluation of renal transplantation candidates: Clinical practice guidelines. Am J Transpl 2001;1:3-95.

11. Abbud-Filho M, Adams PL, Alberu J, Cardella C, Chapman J, Cochat $\mathrm{P}$, et al A report of the Lisbon Conference on the care of the kidney transplant recipient. Transplantation 2007;83:S1-22.

12. Block GA, Klassen PS, Lazarus JM, Ofsthun N, Lowrie EG, Chertow GM. Mineral metabolism, mortality, and morbidity in maintenance hemodialysis. J Am Soc Nephrol 2004;15:2208-18.

13. Chronic Kidney Disease Prognosis C, Matsushita K, van der Velde M, Astor BC, Woodward M, Levey AS, et al Association of estimated glomerular filtration rate and albuminuria with all-cause and cardiovascular mortality in general population cohorts: a collaborative meta-analysis. Lancet 2010;375:2073-81. 
14. McCullough PA. Contrast-induced acute kidney injury. J Am Coll Cardiol 2008;51:1419-28.

15. Workgroup KD. K/DOQI clinical practice guidelines for cardiovascular disease in dialysis patients. Am J Kidney Dis 2005;45:S1-153.

16. Weinrauch L, D'Elia JA, Healy RW, Gleason RE, Christleib AR, Leland OS Jr. Asymptomatic coronary artery disease: angiographic assessment of diabetics evaluated for renal transplantation. Circulation 1978;58:1184-90.

17. Braun WE, Phillips DF, Vidt DG, Novick AC, Nakamoto S, Popowniak KL, et al Coronary artery disease in 100 diabetics with end-stage renal failure. Trans Proc 1984;16:603-7.

18. Lorber MI, Van Buren CT, Flechner SM, Cameron L, Leatherwood J, Walker WE, et al Pretransplant coronary arteriography for diabetic renal transplant recipients. Transpl Proc 1987;19:1539-41.

19. Bennett WM, Kloster F, Rosch J, Barry J, Porter GA. Natural history of asymptomatic coronary arteriographic lesions in diabetic patients with end-stage renal disease. Am J Med 1978; 65:779-84.
20. Weinrauch LA, D'Elia JA, Healy RW, Gleason RE, Takacs FJ, Libertino JA, et al Asymptomatic coronary artery disease: Angiography in diabetic patients before renal transplantation. Relation of findings to postoperative survival. Ann Intern Med 1978;88: 346-8.

21. Hakeem A, Bhatti S, Dillie KS, Cook JR, Samad Z, Roth-Cline $\mathrm{MD}$, et al Predictive value of myocardial perfusion single-photon emission computed tomography and the impact of renal function on cardiac death. Circulation 2008;118:2540-9.

22. Manske CL, Wang Y, Rector T, Wilson RF, White CW. Coronary revascularisation in insulin-dependent diabetic patients with chronic renal failure. Lancet 1992;340:998-1002.

23. Hage FG, Smalheiser S, Zoghbi GJ, Perry GJ, Deierhoi M, Warnock D, et al Predictors of survival in patients with end-stage renal disease evaluated for kidney transplantation. Am J Cardiol 2007;100:1020-5 